\title{
POLÍTICAS PÚBLICAS E AGRICULTURA FAMILIAR: UMA ANÁLISE DO PRONAF NO TERRITÓRIO DO CANTUQUIRIGUAÇU/PR
}

\author{
Luzia Bucco Coelho* \\ Nilson Maciel de Paula**
}

\begin{abstract}
Resumo
Considerando a importância da agricultura familiar para o desenvolvimento rural, bem como seu papel no abastecimento alimentar doméstico do país, este artigo tem como objetivo analisar a operacionalização do Programa Nacional de Fortalecimento da Agricultura familiar (PRONAF) e seus impactos no desenvolvimento rural do território do Cantuquiriguaçu, Paraná, Brasil. Questiona-se em que medida esta política nacional de financiamento da produção, investimento e comercialização da agricultura familiar tem contribuído para um distanciamento dos produtores das cadeias locais de suprimento, descaracterizando sua diversidade produtiva, ao mesmo tempo em que se articulam cada vez mais aos mercados globais de commodities agrícolas. Para tanto, esta análise, embasada por pesquisa empírica, tem caráter exploratório e descritivo, visando a identificar aquelas transformações naquele território, por meio de informações coletadas em 20 entrevistas semiestruturadas com agricultores familiares, organizações e instituições que participam da operacionalização do PRONAF. Por sua vez, as características descritivas foram detectadas a partir de informações relativas ao perfil dos produtores, à estrutura agrária da região estudada e à finalidade do crédito concedido pela política de 1995 a 2017 na região. Os resultados dessa investigação revelam que essa política de crédito tem contribuído para a manutenção de contradições que vêm marcando a agricultura familiar. Enquanto os produtores preservam suas características tradicionais, são também estimulados a se articularem aos mercados globais, produzindo commodities, como soja e milho, e adotando um modelo de desenvolvimento tecnológico típico do agronegócio, no qual predominam grandes propriedades.
\end{abstract}

Palavras-chave: PRONAF. Desenvolvimento rural. Agricultura familiar.

\footnotetext{
* Doutoranda em Desenvolvimento Rural no Programa de Pós-Graduação em Desenvolvimento Rural da Universidade Federal do Rio Grande do Sul (UFRGS). E-mail: luziabucco@gmail.com

** Pós-doutor pela University of Reading, UK. Professor no Programa de Pós-Graduação em Políticas Públicas da Universidade Federal do Paraná (UFPR). E-mail: nilson@ufpr.br
} 


\section{Introdução}

Após ter sido negativamente afetada pelas profundas mudanças ocorridas na agricultura brasileira, decorrentes de uma forte concentração fundiária e ampla difusão de novas tecnologias desde a década de 1960, a agricultura familiar, enquanto categoria social e econômica, ganhou destaque no meio acadêmico e na agenda da política agrícola. Tendo em vista sua incontestável importância no abastecimento alimentar brasileiro, a agricultura familiar passou, a partir de meados dos anos de 1990, a ser contemplada por políticas públicas de incentivo à produção e comercialização, de preços mínimos e de seguro da produção, visando a melhorar seu padrão de vida e promover melhores condições produtivas e de inserção nos mercados (SCHNEIDER, 2006).

As questões tratadas neste artigo referem-se especificamente à execução do Programa Nacional de Fortalecimento da Agricultura Familiar (PRONAF) e a seus impactos no desenvolvimento rural no território do Cantuquiriguaçu, Paraná. Tendo como referência inicial o processo de ocupação da região, é analisada a sobrevivência dos produtores familiares naquele espaço, por meio do engajamento social e institucional na execução dessa política, no tocante às atividades produtivas, ao padrão tecnológico e às relações mercantis. A delimitação geográfica desta análise compreende a escala territorial introduzida nas políticas públicas do Ministério do Desenvolvimento Agrário (MDA), pelo programa Territórios da Cidadania, em 2008, paralelamente à vigência do PRONAF desde sua implantação, em 1995, até o ano de 2017.

Após uma revisão conceitual da agricultura familiar, os rumos do desenvolvimento rural no Território do Cantuquiriguaçu são analisados, com interesse específico na atuação do Estado através do PRONAF. Para a realização deste trabalho, foram reunidas informações obtidas por meio de entrevistas semiestruturadas com 20 famílias de agricultores familiares e 11 organizações a eles ligadas, como o Instituto Paranaense de Assistência Técnica e Extensão Rural (EMATER), o Sindicato dos Trabalhadores Rurais, a Secretaria de Agricultura Pecuária e Abastecimento, Conselho de Desenvolvimento Territorial do Cantuquiriguaçu (CONDETEC), a Agroindustrial Cooperativa (COAMO), o Banco do Brasil (BB) e as associações de agricultores no período de setembro a dezembro de 2014 em seis municípios do Cantuquiriguaçu, sendo eles: Cantagalo, Candói, Quedas do Iguaçu, Marquinho, Goioxim e Nova Laranjeiras. Os dados quantitativos referentes aos créditos de PRONAF disponibilizados para o território no período de 1995 a 2017 foram obtidos diretamente em consulta ao Banco Central do Brasil (BACEN). Com base nessas informações, constatou-se que os recursos acessados pelos agricultores familiares foram 
na maioria destinados à exploração de commodities como a soja e o milho e que atividades mais diversificadas como fruticultura, bovinocultura leiteira, horticultura e produtos da agroindústria familiar ainda têm pouca participação nos financiamentos pela política.

\section{Agricultura familiar e o desenvolvimento rural: uma revisão}

A sobrevivência da agricultura familiar em meio às profundas transformações capitalistas do meio rural tem sido tema de amplas controvérsias. $\mathrm{O}$ inexorável desaparecimento do pequeno camponês devido à proletarização da força de trabalho no campo, como previsto por Marx, tem sido desafiado pela consolidação de um intenso processo de diferenciação socioeconômica por relações de produção amparadas na família e vinculadas a distintas instâncias de mercado. Assim, paralelamente a um processo de fortalecimento de sistemas produtivos tipicamente capitalistas, a agricultura familiar tem se reproduzido por meio de organização socioeconômica e condições políticas distintas.

Desde a década de 1980, o processo de globalização promoveu significativas transformações econômicas e sociais que afetaram as estruturas produtivas e comerciais, bem como a dinâmica dos mercados consumidores finais. Nesse processo, enquanto alguns países, entre os quais o Brasil, se converteram em plataformas exportadoras de commodities globais de alta produtividade, seus sistemas agroalimentares mantiveram sua complexidade, preservando a agricultura familiar em pequenas propriedades, de ampla diversificação produtiva. Atualmente, de acordo com informação da Organização das Nações Unidas para a Alimentação e Agricultura (FAO, 2017), a agricultura familiar produz em torno de 70\% dos principais alimentos consumidos no país.

Do ponto de vista comercial, apesar de sua elevada importância no abastecimento interno do país, a agricultura familiar não está vinculada a relações mercantis específicas. A integração a complexos agroindustriais e cadeias produtivas de dimensões globais, colocou o agricultor familiar em sintonia com as demandas do capital agroindustrial, por meio de um “[...] processo pelo qual o progresso tecnológico se internaliza e penetra na agricultura, modificando o tipo de relação que o agricultor estabelece com a natureza e os sistemas produtivos" (GAZOLLA; SCHNEIDER, 2004, p. 46). Os mercados são, portanto, uma instância essencial para o entendimento da reprodução desse segmento socioeconômico no campo, o qual não se mantém alheio a transformações estruturais que propiciaram a conexão entre o meio rural e as várias instâncias do sistema agroalimentar, cujas dimensões globais são vez mais proeminentes (SCHNEIDER, 2013).

No entanto, enquanto o mercado gera renda, pode ao mesmo tempo ser uma instância destruidora, proporcionando abastecimento na esfera do 
consumo e gerando escassez na esfera produtiva. O mecanismo de preço que desloca estoques de alimentos para o mercado consumidor pode também deixar sistemas produtivos estáveis e superavitários em condições vulneráveis. Essa armadilha tende a ser implacável para agricultores mais frágeis, incapazes de controlar as oscilações de preço e de manter estoques no âmbito local. No entanto, o agricultor familiar se conecta ao mercado atraído pela perspectiva de retorno econômico, descaracterizando a suposta simbiose entre formas tradicionais de produção e mercados locais.

$\mathrm{Na}$ realidade, essas dimensões não são totalmente excludentes quando observamos as estratégias adotadas pela agricultura familiar que a distanciam cada vez mais do camponês, tanto no sentido chayanoviano de uma lógica própria de reprodução, quanto no sentido "leninista" da diferenciação social rumo ao seu desaparecimento (ABRAMOVAY, 1990). A racionalidade da agricultura familiar, em seus aspectos econômicos, sociais e culturais, consolidou-se no Brasil, particularmente após anos de 1970, por uma sinergia entre mecanismos de sobrevivência que envolvem ganhos proporcionados pela produção de commodities globais, a exemplo da soja, e seus traços socioculturais e econômicos. Seus limites de escala e defasagem tecnológica não são obstáculos para tal estratégia. Igualmente pequenos produtores se vinculam a cadeias produtivas globais, fornecendo produtos a redes de supermercado ou à indústria processadora, a exemplo do que ocorre na avicultura e suinocultura. Portanto, se por um lado a agricultura familiar incorpora a lógica do sistema agroalimentar mundial, por outro preserva uma alteridade com ambiente social formado localmente. Diante disso, os desafios das políticas públicas estão em neutralizar os efeitos destrutivos daquela sinergia, a qual, mesmo sendo contraditória, acaba concentrando renda e posse da terra. Ou seja, o Estado passa a ter um papel de suporte para que agricultura familiar sobreviva, preservando seus traços social e culturalmente construídos, sem que isso signifique, necessariamente, uma estratégia de autoctonia.

\section{A agricultura familiar como alvo da ação do Estado: amplitude e limitações do PRONAF}

De acordo com Schneider (2006), foi em meados de 1990 que a expressão agricultura familiar emergiu no contexto brasileiro. Em grande parte, esse movimento de valorização do segmento como categoria social deveu-se ao contexto marcado pela nova constituição e por um ambiente de maiores liberdades políticas. Adiciona-se a isso um protagonismo mais contundente dos movimentos sociais organizados na esteira do crescente reconhecimento de uma identidade socioeconômica da agricultura familiar. Nesse interim, o padrão produtivo concentrador de renda e da grande escala foi questionado pelos movimentos sociais, retomando bandeiras 
reformistas e reivindicando uma reorientação da política agrícola na direção de pequenos agricultores familiares. Embora a agricultura familiar, sob denominações distintas de pequenos produtores, camponeses, etc. fosse indiretamente contemplada por diversos instrumentos de política agrícola em períodos anteriores, preocupações com sua fragilidade passaram a ter espaço institucional.

Por um lado, a Confederação Nacional dos Trabalhadores da Agricultura (CONTAG) e o Departamento Nacional de Trabalhadores Rurais da Central Única dos Trabalhadores (DNTR/CUT) passaram a pleitear uma reestruturação produtiva dos agricultores familiares, que seriam afetados pelo processo de abertura da economia. Com isso, as reivindicações dos trabalhadores rurais, já incluídas na Constituição de 1988, ganharam destaque nas Jornadas Nacionais de Luta na primeira metade da década de 1990 e, a partir de 1995, passaram a ser denominadas "Grito da Terra Brasil" (MATTEI, 2006).

Impulsionado pelos movimentos por reformas estruturais, pela CONTAG, pelo Instituto Nacional de Colonização e Reforma Agrária (INCRA), e pela Organização das Nações Unidas para Alimentação e Agricultura (FAO), foi criada, em 1995, a primeira política pública específica para a agricultura familiar, o PRONAF, por meio do qual o segmento social da agricultura familiar ganhou uma identidade e o reconhecimento como categoria social específica (GAZOLLA; SCHNEIDER, 2004). Desde então, o PRONAF tem sido uma das principais ações do Estado junto à agricultura familiar.

O objetivo principal do programa, quando lançado em 1996, era fortalecer as atividades do agricultor familiar, integrá-lo à cadeia agroindustrial, aumentar sua renda e agregar valor ao produto e à propriedade, mediante a profissionalização e a valorização dos produtores e de suas famílias. A proposta do programa era melhorar a qualidade de vida dos agricultores familiares, promovendo o desenvolvimento rural de forma sustentada. Esse objetivo deveria ser alcançado por meio do aumento da capacidade produtiva, com a adoção de novas tecnologias bem como de investimentos em infraestrutura física e social, de forma a proporcionar suas condições competitivas. Paralelamente, os objetivos do PRONAF foram ajustados visando a dar maior apoio à produção de alimentos. Assim, sua execução tinha

[...] como base a produção de alimentos para o próprio consumo ou para a segurança alimentar da população em geral; contribuindo na valorização do trabalho familiar e para o desenvolvimento sustentável do campo diferentemente da agricultura patronal ou industrial que utiliza o modelo de monocultura e latifúndio de commodities agrícolas, gerando exploração do trabalho agrícola, desigualdade e degradação ambiental. (BRASIL, 2006).
1 De acordo com a CONTAG, o Grito da Terra foi a principal ação de massa do Movimento Sindical de Trabalhadores e Trabalhadoras Rurais (MSTTR), promovido pela CONTAG, Federações dos Trabalhadores na Agricultura (FETAGS) e pelos Sindicatos dos Trabalhadores e Trabalhadoras Rurais (STTRS). Reuniu anualmente, na capital federal, pessoas de todo o país, entre lideranças, agricultores(as) familiares, assalariados(as) rurais, assentados(as) e acampados(as) da reforma agrária, entre outros que apoiam as bandeiras de luta da população rural. 
2 Campo Bonito, Candói, Cantagalo, Catanduvas, Diamante do Sul, Espigão Alto do Iguaçu, Foz do Jordão, Goioxim, Guaraniaçu, Ibema, Laranjeiras do Sul, Marquinho, Nova Laranjeiras, Pinhão, Porto Barreiro, Quedas do Iguaçu, Reserva do Iguaçu, Rio Bonito do Iguaçu, Três Barras do Paraná e Virmond.
Entretanto, embora os aspectos normativos tratassem dessa vocação para a produção de alimentos, o programa revelou fragilidades, entre as quais o desequilíbrio na distribuição regional dos recursos, cuja maior parte, desde seu lançamento, tem sido destinada aos estados do sul, enquanto cerca de 50\% dos agricultores familiares do país estão localizados na região Nordeste (IBGE, 2009). De acordo com informações do BACEN (2018), do total do crédito liberado para custeio da produção entre 1995 e 2015, cerca de $75 \%$ dos recursos foram concentrados em quatro estados, Rio Grande do Sul (31\%), Paraná (18\%), Santa Catarina (14\%) e Minas Gerais $(12, \%)$, enquanto 16 estados receberam menos de $1 \%$ dos recursos totais. Essa concentração é observada também no que se refere ao número de contratos do PRONAF, visto que 33\% foram assinados no Rio Grande do Sul, 14\% no Paraná, 12\% em Santa Catarina e 10\% em Minas Gerais.

Além da concentração na distribuição dos recursos, outro aspecto relevante sobre a política pública do PRONAF diz respeito à especialização produtiva gerada pelo programa e seu direcionamento para determinados mercados. Para Schneider e Aquino (2010), quando fomenta o padrão de desenvolvimento produtivista assentado no uso de insumos químicos, a política promove a especialização dos agricultores familiares na produção de commodities.

Nesse sentido, essa desproporção na distribuição dos recursos explica-se em parte pela maior integração dos agricultores familiares da região Sul aos mercados, pelo uso mais intenso de insumos agrícolas e pela melhor estrutura de assistência técnica oficial, comparada às demais regiões. Além disso, destaca-se a pressão mais eficaz dos movimentos locais junto ao governo e ao sistema bancário (CASTRO, RESENDE; PIRES, 2014).

Apesar das críticas às limitações do programa, na história da agricultura familiar brasileira, esta é uma das principais políticas públicas de crédito com capilaridade nacional adequada a essa categoria social. Daí a importância de analisar seus impactos na dinâmica econômica, social e cultural de uma região específica, já que tornam possível identificar o engajamento dos diferentes atores produtivos, institucionais e associativos no desenvolvimento rural deste espaço. Para tanto, a seguir, a atenção está voltada aos impactos dessa política no território de Cantuquiriguaçu, Paraná, onde a agricultura familiar é bastante representativa.

\section{Agricultura familiar no território do Cantuquiriguaçu}

O território do Cantuquiriguaçu localiza-se no Terceiro Planalto Paranaense, entre as mesorregiões geográficas Centro-Sul e Oeste do estado do Paraná e abrange uma área de $14 \mathrm{mil} \mathrm{km}$, sendo formado por 20 municípios $^{2}$ (Mapa 1). Sua população total, segundo o Censo Populacional 
do Instituto Brasileiro de Geografia e Estatística (IBGE) de 2010, era de 232.519 habitantes, $46 \%$ deles vivendo no meio rural. O espaço rural paranaense carrega a herança de um processo de ocupação por meio do latifúndio e da atividade extrativa e predatória de baixo dinamismo. Segundo o Instituto Paranaense de Desenvolvimento Econômico e Social (IPARDES, 2004), por um longo período, a região esteve sujeita a uma quase total ausência de infraestrutura viária, fato que dificultou sua integração com outras regiões do Estado e freou o processo de sua ocupação.

No período posterior aos anos de 1960, a modernização agrícola do Paraná, que iniciou em algumas regiões, gradativamente se estendeu a todas as áreas do estado, a modernização foi acompanhada de mudanças produtivas e tecnológicas, com graves repercussões sociais, entre as quais o êxodo rural, a concentração fundiária e o desemprego no campo (PRIORI et al., 2012). Como parte desse processo, o êxodo rural foi influenciado pela substituição das culturas permanentes por monoculturas temporárias como a soja, o trigo e o milho - cujo resultado foi a redução do uso de mão de obra no campo e, em particular, do emprego permanente. Isso porque, essas lavouras contavam com um alto nível de mecanização, o que acabou reduzindo o uso de mão de obra, diferentemente do que era observado no caso da erva-mate e da indústria madeireira.

\section{Mapa 1 - Municípios do território do Cantuquiriguaçu}

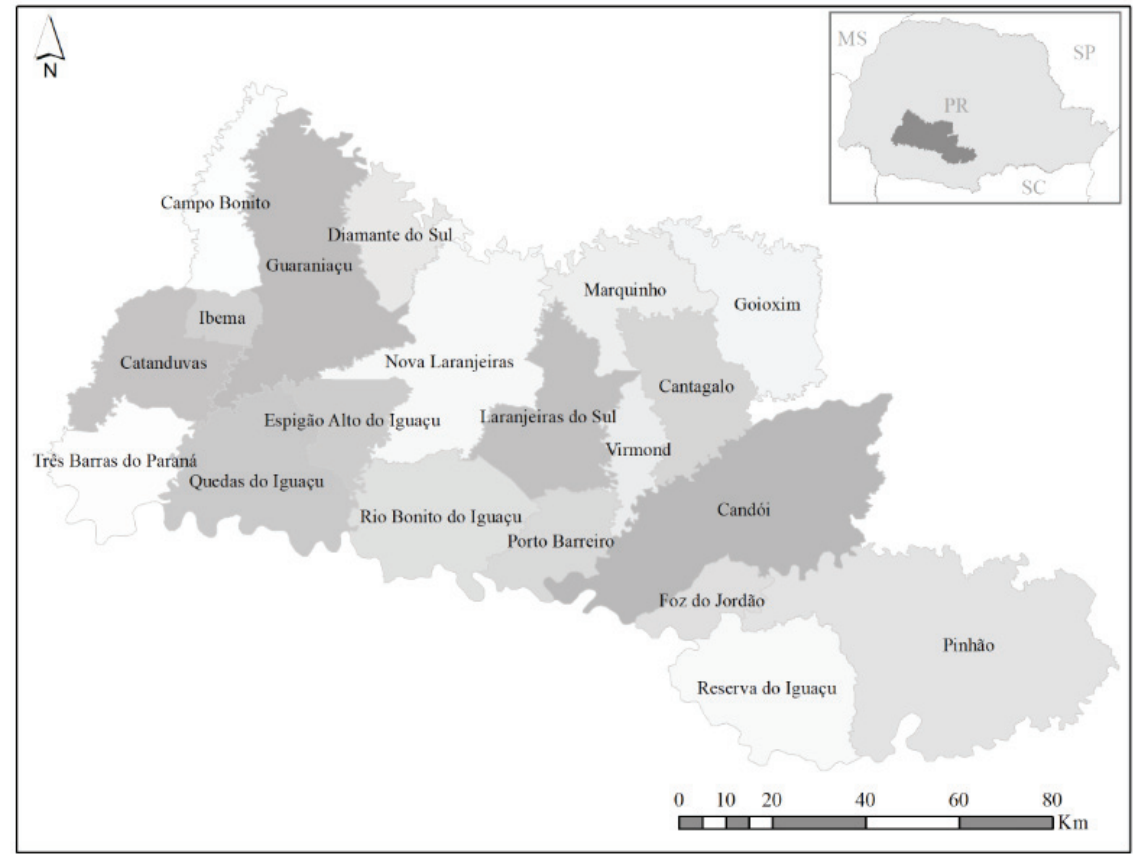

Fonte: Adaptado de Instituto Paranaense de Desenvolvimento Econômico e Social (2007).

No período posterior aos anos de 1980, houve mudanças devido ao fato de a região comportar vários assentamentos populacionais, as quais 
reforçaram sua característica fundiária predominantemente centrada na agricultura familiar. De acordo com informações do Censo Agropecuário de 2006, havia 25.463 estabelecimentos agropecuários distribuídos de forma heterogênea entre os municípios do território neste período, devido ao relevo acidentado, à fertilidade e ao tipo de solo - fatores que favoreciam atividades produtivas de baixa escala. Desse total de estabelecimentos agropecuários, aqueles que utilizavam mão de obra familiar representam $84 \%$ do total, contra $16 \%$ da agricultura não familiar. Ao mesmo tempo, $79 \%$ dos estabelecimentos familiares obtiveram receitas e eram economicamente ativos, enquanto na agricultura não familiar essa proporção chegou a 84\%.

Embora o processo modernizante tenha trazido mudanças na estrutura agrária e produtiva do território de Cantuquiriguaçu, onde predominam estabelecimentos da agricultura familiar de pequena escala, suas repercussões no conjunto da economia regional concentraram-se principalmente nas atividades agrícolas. Com isso, a base econômica do território permaneceu visivelmente concentrada em atividades primárias, cujas externalidades não têm sido suficientes para a formação de uma estrutura agroindustrial ou mesmo para proporcionar mudanças no conjunto da economia regional.

\section{Impactos do PRONAF no território do Cantuquiriguaçu}

Embora os recursos do PRONAF tenham aumentado consideravelmente desde sua implementação em 1995, seus impactos mais perceptíveis manifestam-se especialmente na produção agrícola, sugerindo que o programa possui um viés com base no aumento da produção agrícola. O modelo de produção agropecuária assim financiada está fortemente centrado na utilização dos chamados “insumos modernos”, os quais elevam sequencialmente a dependência econômica e social dos agricultores de um padrão produtivo, cuja sustentabilidade demonstra sinais de esgotamento (MATTEI et al., 2007).

Quanto à distribuição dos recursos do PRONAF no território do Cantuquiriguaçu, observa-se uma evolução dos valores liberados para crédito de custeio e investimento até o ano de 2015 (Tabela 1), a partir de quando, as contratações - tanto de custeio quanto de investimento têm diminuído no território (Gráficos 1 e 2). A modalidade de custeio que iniciou com 255 contratos em 1995 (valor médio $\mathrm{R} \$ 6.297,69$ ), mas chegou, em 2004, a 10.847 contratos com valor médio de $\mathrm{R} \$ 6.274,18$. No entanto, após esse período, o número de contratos passou a oscilar chegando a 6.341 no ano de 2015, com valor médio de $\mathrm{R} \$ 41.002,29$ e, no ano de 2017 , a 4.376 contratos com valor médio de $\mathrm{R} \$ 36.377,97$. Acredita-se que essa mudança do valor médio e a diminuição do número de contratos possam 
estar atreladas à concentração dos financiamentos em torno de commodities de soja e milho, que foram os produtos mais beneficiados na modalidade de custeio durante o período analisado, conforme está detalhado nos Gráficos 3 e 4.

Tabela 1 - Evolução dos créditos Rurais do PRONAF - custeio de investimento no território do Cantuquiriguaçu - PR (1995 - 2017). Número de contratos, R\$ em valores reais e \%

\begin{tabular}{|c|c|c|c|c|c|c|c|c|}
\hline Ano & Contratos & $\begin{array}{c}\text { Evolução } \\
-\%\end{array}$ & Custeio & $\begin{array}{c}\text { Evolução } \\
-\%\end{array}$ & Contratos & $\begin{array}{c}\text { Evolução } \\
-\%\end{array}$ & Investimento & $\begin{array}{c}\text { Evolução } \\
-\%\end{array}$ \\
\hline 1995 & 255 & 100,00 & $1.605 .911,14$ & 100 & & & & \\
\hline 1996 & 2292 & 898,82 & $15.043 .343,98$ & 936,75 & & & & \\
\hline 1997 & 2805 & 1100,00 & $14.534 .026,23$ & 905,03 & 260 & 100,00 & $4.757 .961,07$ & 100,00 \\
\hline 1998 & 6306 & 2472,94 & $23.463 .299,92$ & 1461,06 & 17 & 6,54 & $206.039,19$ & 4,33 \\
\hline 1999 & 9498 & 3724,71 & $39.232 .240,43$ & 2442,99 & 1267 & 487,31 & $14.931 .348,26$ & 313,82 \\
\hline 2000 & 9459 & 3709,41 & $44.621 .636,71$ & 2778,59 & 888 & 341,54 & $11.212 .576,49$ & 235,66 \\
\hline 2001 & 9611 & 3769,02 & $51.239 .218,60$ & 3190,66 & 788 & 303,08 & $22.975 .947,70$ & 482,89 \\
\hline 2002 & 9682 & 3796,86 & $42.889 .533,74$ & 2670,73 & 600 & 230,77 & $15.044 .943,39$ & 316,21 \\
\hline 2003 & 9595 & 3762,75 & $54.749 .874,23$ & 3409,27 & 1251 & 481,15 & $20.903 .290,74$ & 439,33 \\
\hline 2004 & 10847 & 4253,73 & $68.055 .990,14$ & 4237,84 & 2379 & 915,00 & $23.050 .415,30$ & 484,46 \\
\hline 2005 & 9184 & 3601,57 & $68.901 .040,26$ & 4290,46 & 1721 & 661,92 & $35.084 .116,61$ & 737,38 \\
\hline 2006 & 8829 & 3462,35 & $67.478 .430,22$ & 4201,88 & 3042 & 1170,00 & $45.701 .163,95$ & 960,52 \\
\hline 2007 & 8476 & 3323,92 & $76.941 .529,02$ & 4791,14 & 2078 & 799,23 & $38.252 .492,04$ & 803,97 \\
\hline 2008 & 7338 & 2877,65 & $98.709 .567,70$ & 6146,64 & 2092 & 804,62 & $55.784 .816,12$ & $1.172,45$ \\
\hline 2009 & 6123 & 2401,18 & $77.323 .554,42$ & 4814,93 & 1886 & 725,38 & $74.603 .419,24$ & $1.567,97$ \\
\hline 2010 & 5719 & 2242,75 & $77.586 .069,07$ & 4831,28 & 3646 & 1402,31 & $87.520 .368,93$ & $1.839,45$ \\
\hline 2011 & 5850 & 2294,12 & $103.087 .351,28$ & 6419,24 & 2919 & 1122,69 & $97.550 .130,38$ & $2.050,25$ \\
\hline 2012 & 6451 & 2529,80 & $137.404 .228,03$ & 8556,15 & 3634 & 1397,69 & $133.653 .493,12$ & $2.809,05$ \\
\hline 2013 & 6783 & 2660,00 & 201.283.681,61 & 12533,92 & 4791 & 1842,69 & $272.161 .875,89$ & $5.720,14$ \\
\hline 2014 & 6683 & 2620,78 & $221.740 .591,35$ & 13807,77 & 3823 & 1470,38 & $322.829 .562,75$ & $6.785,04$ \\
\hline 2015 & 6341 & 2486,67 & $259.995 .516,62$ & 16189,91 & 2669 & 1026,54 & $254.819 .144,52$ & $5.355,64$ \\
\hline 2016 & 5110 & 2003,92 & $126.855 .731,14$ & 7899,30 & 530 & 203,85 & $43.025 .279,20$ & 904,28 \\
\hline 2017 & 4376 & 1716,08 & $116.305 .232,68$ & 7242,32 & 581 & 223,46 & $26.768 .749,90$ & 562,61 \\
\hline Total & 157.613 & & $1.989 .047 .598,52$ & & 40.862 & & $1.600 .837 .134,79$ & \\
\hline
\end{tabular}

Dados atualizados pelo índice IGP-DI (FGV), informações de 08/2018.

Fonte: Adaptada de Banco Central do Brasil (2018).

Por sua vez, os agricultores familiares entrevistados no território apontaram que a utilização dos recursos de custeio é importante para a atividade produtiva desenvolvida pelas famílias, pois facilita a aquisição de insumos, sementes e defensivos para a lavoura, uma vez que, com o pagamento à vista, consegue-se melhor preço e poder de barganha junto aos fornecedores que em sua maioria são agropecuárias e cooperativas locais. Outra vantagem citada por esses agricultores é o Programa de Garantia da 
3 O Programa de Garantia da Atividade Agropecuária (PROAGRO) garante a exoneração de obrigações financeiras relativas à operação de crédito rural de custeio, cuja liquidação seja dificultada pela ocorrência de fenômenos naturais, pragas e doenças que atinjam rebanhos e plantações, na forma estabelecida pelo Conselho Monetário Nacional (CMN). O PROAGRO foi criado pela Lei 5.969/1973 e é regido pela Lei Agrícola 8.171/1991, ambas regulamentadas pelo Decreto 175/1991 (BRASIL, 2018).

4 O Programa de Garantia de Preços para a Agricultura Familiar (PGPAF) garante aos agricultores familiares com financiamento no âmbito do Pronaf a indexação do financiamento a um preço de garantia igual ou próximo do custo de produção e nunca inferior ao estabelecido na PGPM, assegurando a remuneração dos custos de produção aos agricultores. $\mathrm{O}$ preço de garantia tem por base o custo variável que inclui remuneração de mão-de-obra familiar, da gestão da unidade de produção e dos custos dos insumos e serviços utilizados, com incremento ou redução de até $10 \%$ sobre o valor levantado a campo (BRASIL, 2008).

5Lançadoem 2008,oMais Alimentos busca incrementar a produção e a produtividade, por meio da redução dos custos de produção, elevando a renda da agricultura familiar com linha de crédito direcionada à modernização da infraestrutura das unidades produtivas e da realização de parceria com a indústria nacional para ofertar produtos a preços mais acessíveis. Atualmente o PRONAF Mais Alimentos destina recursos para investimentos em infraestrutura da propriedade rural, sendo $\mathrm{R} \$$ 330 mil o limite máximo para as atividades de suinocultura, avicultura, aquicultura, carcinicultura (criação de crustáceos) e fruticultura e $\mathrm{R} \$$ 165 mil para as demais finalidades. Para financiamento de estruturas de armazenagem, o prazo pode chegar a 15 anos, com até três anos de carência. Para projetos coletivos, o limite é de $\mathrm{R} \$ 800$ mil (BRASIL, 2008).
Atividade Agropecuária (PROAGRO ${ }^{3}$ ), que, em tempos de adversidade climática, ajudou na permanência das famílias na atividade rural, pois muitas pessoas deixaram suas comunidades em anos de safras ruins, algumas inclusive precisaram vender bens para cobrir prejuízos e sobreviver no meio rural. Além disso, os agricultores mencionaram o Programa de Garantia de Preços para a Agricultura Familiar (PGPAF) ${ }^{4}$, principalmente no caso do milho, que é utilizado na rotação de cultura e alimentação dos animais.

A partir da análise das informações relativas à distribuição de recursos do PRONAF e aquelas obtidas em entrevistas com agricultores familiares, percebe-se que o PRONAF tem estimulado mudanças técnicas e produtivas na agricultura familiar segundo princípios de produtividade e rentabilidade crescentes. Isso, de acordo com Gazolla e Schneider (2013) tem sido uma contradição para o programa. Por ser uma política de desenvolvimento rural com ênfase na diversificação das atividades produtivas rurais, em grande medida também se configura como uma política de desenvolvimento agrícola ao financiar a incorporação de tecnologias modernas e incentivar a produção de commodities globais.

Ainda no território do Cantuquiriguaçu, há sinais de maior adoção de tecnologia impulsionada pelo PRONAF. Os financiamentos para investimento, utilizados para a adquirir estruturas para implantar, ampliar ou modernizar as propriedades e a estrutura de produção, evoluíram principalmente no período de 1995 a 2014, tanto em número de contratos quanto em recursos liberados (Gráfico 1 e 2). Em 1997, foram realizados 260 contratos com valor médio de $\mathrm{R} \$ 18.299,85$; em 2015, 2669 contratos, estes com valor médio de $\mathrm{R} \$ 95.473,64)$. Parte desse crescimento se deve à criação da Linha Mais Alimentos ${ }^{5}$ em 2008, quando houve melhorias nas condições de pagamento e diminuição dos juros cobrados nos financiamentos. De toda forma, assim como na modalidade custeio, os últimos dois anos analisados (2016 e 2017) apresentaram decréscimo em números de contratos e valores distribuídos no território como pode se observar na Tabela 1 e Gráficos 1 e 2.

Quanto ao tipo de atividade produtiva apoiada e à concentração de recursos nas atividades financiadas pelo PRONAF, de acordo com Leite (2001), há uma visível concentração dos recursos para produção de commodities, principalmente de milho e soja, cenário também observado no Cantuquiriguaçu, cujos dados de financiamento de custeio de 1995 a 2008 apontam o milho como o principal produto financiado. A partir de 2008, o financiamento de custeio para soja cresceu e tornou-se o principal produto beneficiado com os recursos do programa, embora, no total financiado de 1995 a 2017 (Gráfico 3), o milho ainda figure como a cultura que recebeu $41,89 \%$ dos recursos na região, e a soja 30,59\%. 
Gráfico 1- Crédito rural (R\$) de PRONAF - custeio e investimento concedidos aos municípios do território do Cantuquiriguaçu, Paraná - 1995 a 2017

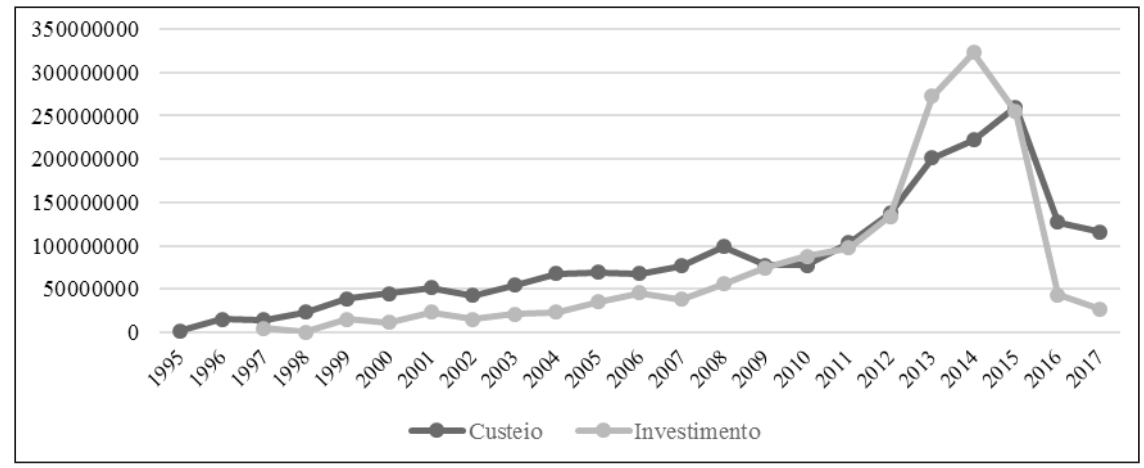

Dados atualizados pelo índice IGP-DI (FGV), informações de 08/2018.

Fonte: Adaptado de Banco Central do Brasil (2018).

Embora a bovinocultura de leite e corte tenha evoluído consideravelmente entre os agricultores da região, no que se refere a financiamentos pelo PRONAF os valores para essas atividades absorvem apenas $10,7 \%$ do total financiado desde o início do programa. Já o financiamento destinado à produção de alimentos ${ }^{6}$ no território participou com aproximadamente $14,6 \%$ do total dos recursos no período de 1995 a 2017, sendo alavancado pela bovinocultura principalmente.

Gráfico 2 - Número de contratos de custeio e investimento concedidos aos municípios do território Cantuquiriguaçu, Paraná - 1995 a 2017

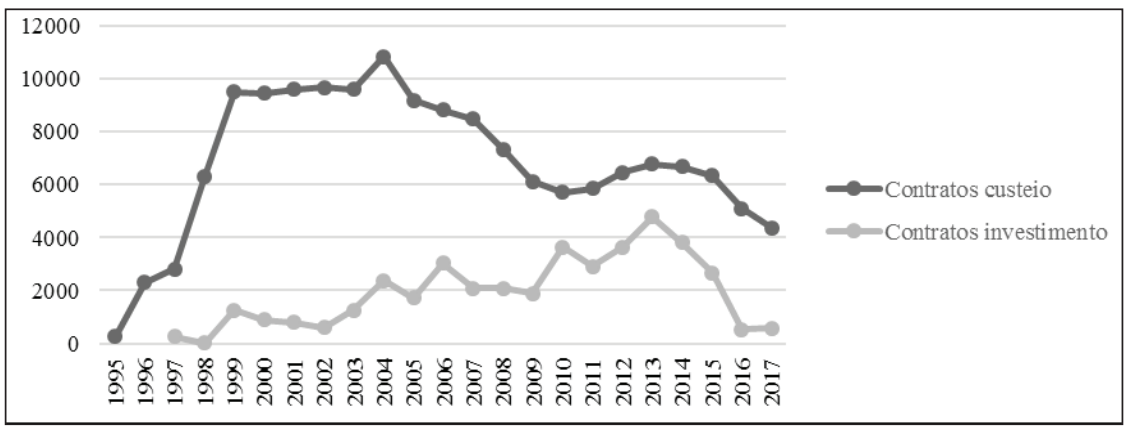

Dados atualizados pelo índice IGP-DI (FGV), informações de 08/2018

Fonte: Adaptado de Banco Central do Brasil (2018).

O fomento à produção de grãos e commodities agrícolas, com destaque para o milho e a soja (Gráfico 3 e 4), mostram que o PRONAF tem fortalecido a inserção produtiva da agricultura familiar, já que se percebe maior especialização produtiva das unidades, processos crescentes de mercantilização e o uso mais intensivo de inovações nas propriedades familiares. Essa dinâmica tem se destacado entre os agricultores que acessam o programa, ratificando observações feitas por Gazolla e Schneider (2013)
6 Nesse caso, estão incluídas frutas e hortaliças, trigo, feijão, bovinos de carne e leite, excluídas as commodities, fumo e outros financiamentos. 
Gráfico 3 - Distribuição dos recursos do crédito para custeio por produtos (soma dos valores de 1995 a 2017) - Cantuquiriguaçu, Paraná

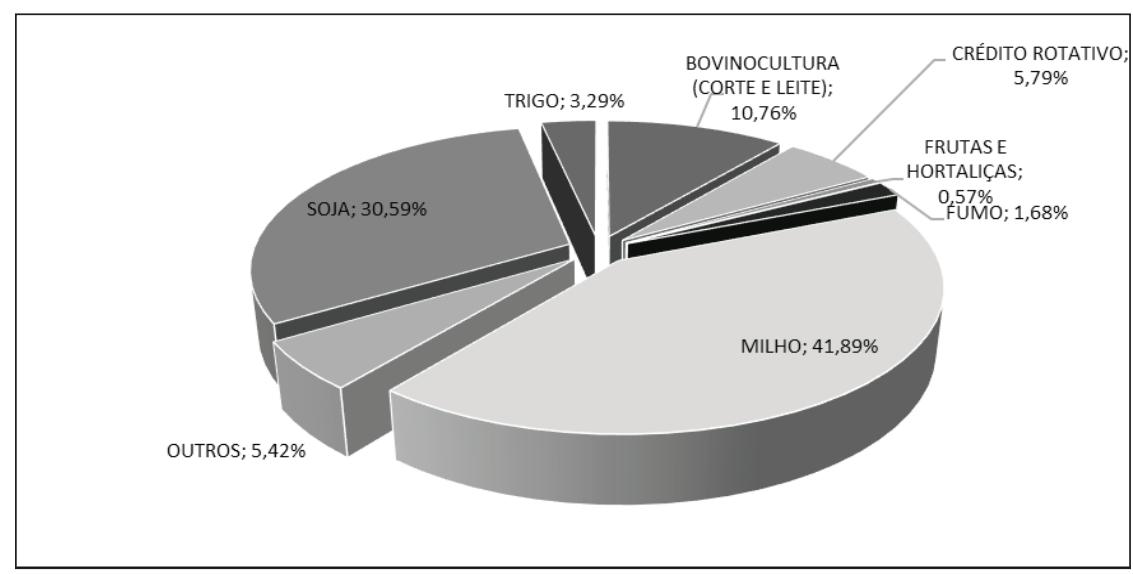

Dados atualizados pelo índice IGP-DI (FGV), informações de 08/2018.

Fonte: Adaptado de Banco Central do Brasil (2018).

Atualmente, no território do Cantuquiriguaçu, o PRONAF tem apoiado principalmente a produção de commodities como a soja e o milho (Gráfico 4), por estas culturas proporcionarem maior retorno relativo. Todavia, algumas alterações ocorreram nas atividades financiadas uma vez que o microcrédito teve participação considerável no início do programa. Menção deve ser feita à proibição de financiamento ao fumo ${ }^{6}$. Lentamente se percebe um ingresso de outros produtos, iniciado em 2005/2006, quando atividades como a produção de leite, carne e feijão começaram a avançar.

Entre as 20 famílias de agricultores entrevistados na região (Gráfico 5), apenas 25\% deles nunca utilizaram recursos do PRONAF, 20\% utilizaram somente para custeio, $15 \%$ apenas para investimento e $40 \%$ tiveram acesso a ambas as modalidades. Sobre a razão para a utilização dos recursos, grande parte dos agricultores se referiu aos juros baixos de longo prazo para pagamento do investimento, à possibilidade de iniciar novas atividades como a bovinocultura leiteira, com vacas de melhor genética e aumento da produção de leite, e à modernização da propriedade e dos implementos utilizados. 
Gráfico 4 - Créditos rurais de PRONAF - custeio por produto ${ }^{7}$ nos municípios do território do Cantuquiriguaçu, Paraná -janeiro/1995 a junho/2017

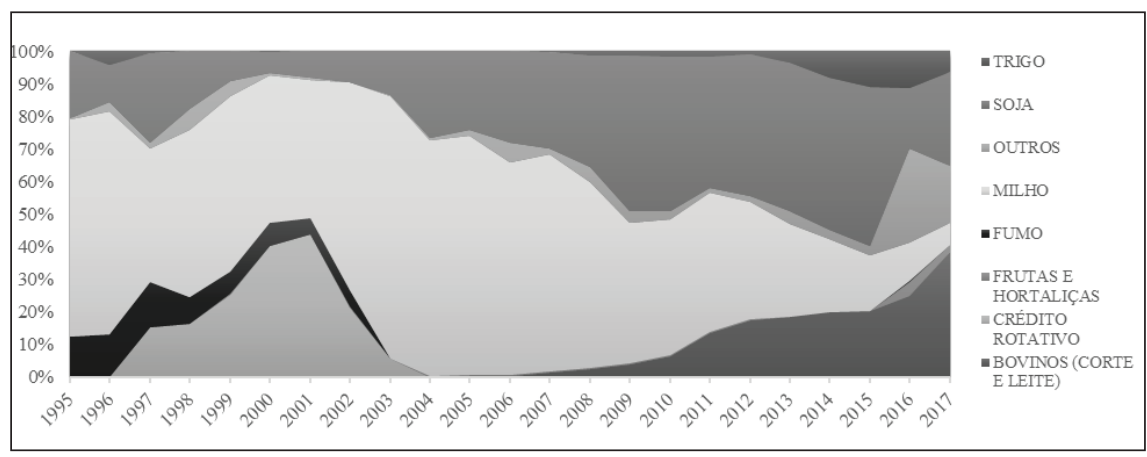

Dados atualizados pelo índice IGP-DI (FGV), informações de 08/2018.

Fonte: Adaptada de Banco Central do Brasil (2018).

Por outro lado, dificuldades foram citadas a propósito da regularização fundiária na região, por questões hereditárias de transmissão das propriedades e falta de título oficial do INCRA. Com isso, os recursos do PRONAF, principalmente de investimento, não podem ser acessados. As garantias e o processo de contratação com as agências bancárias também foram citados como empecilho, devido à burocracia do processo e também pelo fato de aqueles que não possuem imóveis ou bens para penhorar devem recorrer a avalistas, o que dificulta o crédito principalmente a agricultores que pretendem iniciar a atividade ou acessar pela primeira vez o programa.

\section{Gráfico 5 -Tipos de acesso ao PRONAF entre os agricultores entrevistados}

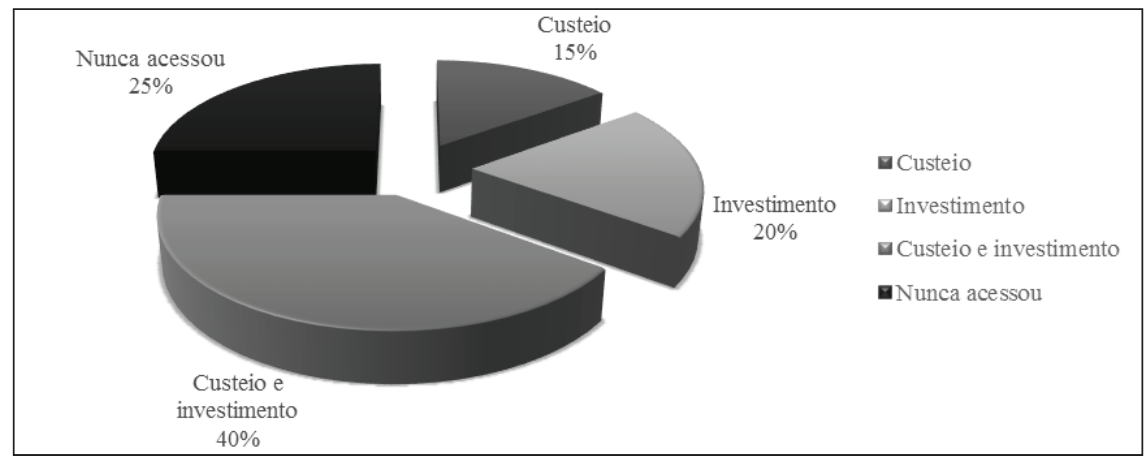

Dados da Pesquisa de campo.

Fonte: Elaborado pelos autores (2018).

Entre as principais mudanças ocorridas no território desde a implementação do PRONAF destaca-se a mudança na composição das atividades escolhidas pelas famílias. De acordo com o relato dos agricultores, muitos alimentos que eram cultivados nas propriedades passaram a ser comprados nos mercados locais, porque ocupar a área com soja e milho é mais rentável e demanda um contingente menor de mão de obra. Outra
7 Devido ao número de contratos reduzidos foram agrupadas informações sobre os financiamentos em fruticultura e hortaliças (abóbora, alface, brócolis, cebola, cenoura, couveflor, hortaliças diversas, mandioca, pepino, repolho e tomate) e como outros (arroz, algodão, cana-deaçúcar, girassol, vacinas, aveia e também os contratos com informações ocultas, haja vista que, quando a informação é discriminada por produto, os municípios que contêm até três contratos ficam ocultos, para a preservação do sigilo bancário, conforme exigido pela Lei Complementar no 105/2001).

6 De acordo com consulta ao Manual do Crédito Rural (MCR), capitulo 10, artigo 1 , item 13 , é vedada a concessão de crédito ao amparo do PRONAF relacionado com a produção de fumo desenvolvida em regime de parceria ou integração com indústrias fumageiras, ressalvado o disposto no item 14 , que admite a concessão de financiamento ao amparo do PRONAF a produtores de fumo, desde que o crédito se destine a outras culturas que não o fumo, de modo a fomentar a diversificação das atividades geradoras de renda da unidade familiar. 
8 Sobre a renda média aproximada das famílias, refere-se ao valor bruto de produção anual e foi embasado nas informações recebidas dos entrevistados, com base na quantidade obtida e preço de venda informado na data das entrevistas. mudança importante em termos de atividade produtiva, de acordo com os participantes da pesquisa, foi a inserção da bovinocultura leiteira na região, que deixou de ser produto de subsistência e passou a ser principal fonte de renda para alguns agricultores, e que tem sido alavancada pelos recursos de investimento e custeio via PRONAF.

Nesse sentido, como mostra o Quadro 1, no período da pesquisa de campo, grande parte dos agricultores familiares entrevistados possuía alguma atividade complementar na propriedade, dentre as quais a horticultura, a criação de suínos, e a panificação por exemplo. Essas atividades auxiliavam como complementação da renda, enquanto o cultivo de commodities que ocorria na maior parte das propriedades era considerado a atividade principal. Alguns agricultores ainda precisavam recorrer a atividades que não estavam ligadas à agricultura para sobrevivência, prestando serviços como diarista, pedreiro, funcionário público ou recebendo aposentadoria. É importante ressaltar que a renda ${ }^{8}$ das famílias entrevistadas difere de acordo com a atividade desenvolvida, o número de pessoas envolvidas nas atividades, o grau de tecnologia empregado e a área de terra disponível, cujo valor bruto varia de $\mathrm{R} \$ 3.000,00$ a $\mathrm{R} \$ 12.000,00$.

Percebe-se certa limitação das políticas públicas para modificar o cenário de mercantilização produtiva imposta pelo cultivo de commodities agrícolas. Há, portanto, uma situação estrutural na agricultura determinada por sua dependência às exigências impostas pelo processo de desenvolvimento capitalista no campo e pela prevalência dos mercados globais. Assim, as políticas públicas muitas vezes buscam alternativas a esse padrão convencional de desenvolvimento, como é o caso do PRONAF em sua formulação original. Porém, quando da sua operacionalização junto aos agricultores familiares, esta política acaba estimulando atividades originalmente não contempladas entre seus objetivos, agravando impactos não esperados junto aos agricultores familiares (GAZOLLA; SCHNEIDER, 2013). 
Quadro 1 - Atividades desenvolvidas nas propriedades dos agricultores entrevistados e renda média anual aproximada -2015

\begin{tabular}{|c|c|c|c|c|}
\hline \multirow[b]{2}{*}{ Família } & \multicolumn{4}{|c|}{ Atividades desenvolvidas na propriedade } \\
\hline & Principal & Complementar & $\begin{array}{l}\text { Número de } \\
\text { pessoas }\end{array}$ & $\begin{array}{l}\text { Renda anual } \\
\text { aproximada }\end{array}$ \\
\hline 1 & Milho e soja & Produção de leite, horticultura e fruticultura & 9 & $\mathrm{R} \$ 177 \mathrm{mil}$ \\
\hline 2 & $\begin{array}{l}\text { Horticultura e } \\
\text { fruticultura }\end{array}$ & Produção de Milho & 4 & $\mathrm{R} \$ 24$ mil \\
\hline 3 & Fruticultura & $\begin{array}{c}\text { Criação de carneiros, suinocultura, produção de } \\
\text { cachaça e de pães }\end{array}$ & 3 & $\mathrm{R} \$ 42 \mathrm{mil}$ \\
\hline 4 & Milho & $\begin{array}{c}\text { Produção de leite, suinocultura, serviço de } \\
\text { pedreiro }\end{array}$ & 5 & $\mathrm{R} \$ 35 \mathrm{mil}$ \\
\hline 5 & Leite & Aposentadoria, arrendamento de terras & 1 & $\mathrm{R} \$ 51 \mathrm{mil}$ \\
\hline 6 & Milho e soja & Produção de queijo e de ovos, criação de frango & 4 & $\mathrm{R} \$ 50$ mil \\
\hline 7 & Milho e soja & Produção de leite & 2 & $\mathrm{R} \$ 105$ mil \\
\hline 8 & Milho e soja & Produção de leite & 3 & $\mathrm{R} \$ 82 \mathrm{mil}$ \\
\hline 9 & Agroindústria & Produção de milho e de leite & 4 & $\mathrm{R} \$ 171$ mil \\
\hline 10 & Leite & Produção de milho e feijão & 2 & $\mathrm{R} \$ 25 \mathrm{mil}$ \\
\hline 11 & Leite & Produção de milho & 2 & $\mathrm{R} \$ 80$ mil \\
\hline 12 & Tabaco & Horticultura & 3 & $\mathrm{R} \$ 26 \mathrm{mil}$ \\
\hline 13 & Milho & $\begin{array}{c}\text { Produção de feijão, suinocultura, serviço de } \\
\text { motorista }\end{array}$ & 2 & $\mathrm{R} \$ 21 \mathrm{mil}$ \\
\hline 14 & Leite & $\begin{array}{l}\text { Bovinocultura, suinocultura, serviço de diarista, } \\
\text { bolsa família }\end{array}$ & 4 & $\mathrm{R} \$ 30 \mathrm{mil}$ \\
\hline 15 & Milho e soja & $\begin{array}{c}\text { Produção de leite, serviço de pedreiro e agente } \\
\text { de saúde }\end{array}$ & 3 & $\mathrm{R} \$ 64$ mil \\
\hline 16 & Leite & Suinocultura & 3 & $\mathrm{R} \$ 41 \mathrm{mil}$ \\
\hline 17 & Milho e soja & Produção de leite e feijão & 3 & $\mathrm{R} \$ 25 \mathrm{mil}$ \\
\hline 18 & Milho e soja & Produção de leite & 4 & $\mathrm{R} \$ 30 \mathrm{mil}$ \\
\hline 19 & Leite & Aposentadoria & 2 & $\mathrm{R} \$ 25$ mil \\
\hline 20 & Milho e soja & Bovinocultura & 2 & $\mathrm{R} \$ 150$ mil \\
\hline
\end{tabular}

Dados da Pesquisa de campo.

Fonte: Elaborado pelos autores (2018).

Ainda, pode-se verificar que, apesar de o PRONAF contar com uma gama de linhas de crédito e ter capacidade de apoiar diversas atividades produtivas, no Cantuquiriguaçu, desde sua implementação, ocorreu uma centralização do crédito nas culturas de milho e soja e, em menor grau, na bovinocultura de leite. Nas entrevistas realizadas, foram encontrados agricultores familiares que trabalhavam com horticultura e fruticultura nas propriedades, como atividades complementares, mas que não utilizavam recursos do programa para financiamento. Percebe-se, pela fala dos entrevistados, que há certa tradição em utilizar o crédito apenas para atividades mais representativas em termos de valor monetário. De acordo 
com os agricultores familiares entrevistados, para o cultivo de hortaliças, por exemplo, em que a quantidade plantada e o ciclo de cultivo são menores, não compensaria o trabalho de fazer um projeto, deslocarem-se várias vezes até a instituição financeira e contratarem assistência técnica, porque o processo de empréstimo é padronizado, independentemente do valor e da atividade, e o custo decorrente dessas viagens e organização de documentação não compensaria o pequeno valor a ser financiado com a atividade de horticultura por exemplo. De acordo com um dos agricultores entrevistados: "[...] a burocracia do processo de elaboração até a liberação do crédito faz com que as pessoas desistam do financiamento e até mesmo da atividade".

Nesse interim, quando se trata de políticas públicas para agricultura, a potencialização de algumas ações territoriais pode trazer melhores resultados para a aplicação do crédito, mas estas dependem do grau de integração e comunicação dos envolvidos, bem como de um trabalho contínuo de gestão dessa rede. Percebe-se que essa integração e organização ainda são muito incipientes no Cantuquiriguaçu, em grande parte pela falta de identificação dos agricultores com o território em um sentido que vá além de um mero espaço geográfico. Uma maior organização dos agricultores poderia potencializar os resultados positivos da política pública no território, à medida que forneceria a esses atores as habilidades sociais necessárias.

De acordo com Silva (2009), essa organização dos sistemas locais precisa ocorrer internamente, ou seja, entre os próprios agricultores familiares - por meio de sindicatos, cooperativas e associações - e externamente - pelas redes sociais com outros agentes que atuam no âmbito da operacionalização do PRONAF, como agentes financeiros, entidades de classe, conselhos, ATER etc. -, fortalecendo, assim, um arranjo organizacional mais favorável a eles próprios.

Apesar do amplo debate sobre desenvolvimento rural e agricultura familiar, ainda há muitas nuances em torno dos atores sociais em seus espaços locais, para que se possa compreender as mudanças ocorridas em seu ambiente e a reação das redes sociais às transformações em curso. Há uma expectativa também sobre o futuro da agricultura familiar no meio rural, tendo em vista o esvaziamento do campo em função do envelhecimento da população e da migração para as áreas urbanas.

Sobre o futuro das regiões rurais, nas entrevistas realizadas no território do Cantuquiriguaçu, foram formuladas perguntas sobre seus objetivos como agricultores familiares e o que planejavam para o futuro da família e da propriedade. Nas respostas, 15 das 20 famílias entrevistadas disseram que seu objetivo era a sobrevivência no campo e, como segunda opção, a melhoria de renda. Percebe-se, pelas entrevistas com os agricultores familiares e pelas informações obtidas sobre a distribuição dos recursos, que 
o PRONAF tem viabilizado o acesso às condições para o desenvolvimento das atividades, promovendo infraestrutura e viabilizando a compra de insumos, fertilizantes e equipamentos.

É preciso considerar que a execução de políticas públicas voltadas para a agricultura familiar está sujeita não apenas às necessidades de sobrevivência e manutenção do status quo mas também às expectativas que emanam do próprio segmento quanto a melhorias das condições produtivas e ao aumento de renda. E, para tais questões, a produção de commodities globais pode ser o caminho mais curto.

Nessa perspectiva, a mediação entre essas duas dimensões envolve uma efetiva rede de operacionalização da política pública, infraestrutura de escoamento e comercialização, assistência técnica para acompanhamento das diferentes atividades e compatibilidade das atividades com os recursos naturais disponíveis e valores socioculturais predominantes no âmbito regional.

\section{Considerações finais}

Tendo em vista a predominância da agricultura familiar no território de Cantuquiriguaçu e as condições de vida desses agricultores e de suas relações mercantis, a análise da execução do PRONAF revelou que seus impactos mais visíveis têm se dado por meio do financiamento nas modalidades custeio e investimento. $\mathrm{O}$ aumento do valor médio dos contratos de custeio não apenas sinaliza uma concentração dos recursos contratados em determinadas atividades e em um grupo de agricultores como também revela semelhança com as características do crédito rural brasileiro no período da modernização. A visita a campo permitiu identificar que parte pouco significativa dos recursos do PRONAF tem sido destinada a atividades vinculadas ao mercado local como bovinocultura leiteira, horticultura, fruticultura e industrialização de produtos pela agroindústria familiar. Além disso, há grandes dificuldades no engajamento dos produtores em cadeia de comercialização, fraca sintonia com os mecanismos de preço e padronização de suas atividades, destoando, assim, da forte aderência às commodities globais como soja e milho.

$\mathrm{O}$ caso aqui descrito ilustra como a agricultura familiar tem sobrevivido apesar das mudanças tecnológicas e da necessidade de buscar novos mercados. Com base nas evidências aqui analisadas, a perspectiva da agricultura familiar deve ser situada para além da estrutura produtiva, envolvendo seus mecanismos de reprodução e o papel que desempenham os diversos atores nesses territórios e respectivos mercados. Portanto, a superação do status quo da agricultura familiar na região exige um engajamento dos atores envolvidos na execução de políticas públicas, a exemplo do PRONAF, orientados pela noção de desenvolvimento rural que 
combine eficiência com preservação de valores tradicionais e diversificação da atividade produtiva. Mais ainda, as evidências reunidas nesta análise permitem constatar a agricultura familiar imersa em um ambiente dinâmico que a conduz para novas posições no sistema agroalimentar e nas relações socioeconômicas.

Nesse sentido, não se trata, assim, de uma simples reconstituição do campesinato ou de resistências à penetração do capitalismo no campo, em um resgate de modos de produção e valores culturais tradicionais. Igualmente, não se trata de uma transição inexorável para um sistema empresarial. Em meio a forças conflituosas, nem as tendências leninistas de diferenciação do campesinato, nem as perspectivas de um modo de produção camponês - nos termos de Chayanov - se confirmam. Todavia, tanto movimentos sociais quanto a ação do Estado, com políticas públicas específicas, a exemplo do PRONAF, podem moldar o perfil da agricultura familiar. Nessa espécie de limbo onde lógicas distintas convivem, fragilidades, hesitações ou indefinições do Estado e organizações sociais podem conduzir a agricultura familiar na direção das forças hegemônicas do mercado, agravando seu estado de amorfia e fragilizando suas estruturas sociais e produtivas.

\section{Referências}

ABRAMOVAY, R. De camponeses a agricultores: paradigmas do capitalismo agrário em questão. 1990. 354 f. Tese (Doutorado em Filosofia e Ciências Humanas) - Instituto de Filosofia e Ciências Humanas Universidade Estadual de Campinas, Campinas, 1990. Disponível em: http://www.repositorio.unicamp.br/ handle/REPOSIP/280654. Acesso em: 13 set. 2018.

BANCO CENTRAL DO BRASIL (BACEN). Manual do Crédito Rural (MCR). Disponível em: http://www3.bcb.gov.br/mcr. Acesso em: 13 set. 2018.

BANCO CENTRAL DO BRASIL (BACEN). Correção de valores. Disponível em: https://www3.bcb.gov.br/CALCIDADAO/publico/ exibirFormCorrecaoValores.do?method=exibirFormCorrecaoValores. Acesso em: 13 set. 2018.

BANCO CENTRAL DO BRASIL (BACEN). Matriz de Dados do Crédito Rural (MDCR). Disponível em: https://dadosabertos.bcb.gov.br. Acesso em: 11 set. 2018.

BRASIL. Conselho Nacional de Segurança Alimentar e Nutricional. A segurança alimentar e nutricional e o direito humano à alimentação adequada no Brasil Indicadores e Monitoramento da Constituição de 1988 aos dias atuais. Brasília: CONSEA, 2010.

BRASIL. Secretaria Especial de Agricultura Familiar e do Desenvolvimento Agrário. Mais Alimentos. 2008. Disponível em: http://www.mda.gov.br/sitemda/ secretaria/saf-pgpaf/sobre-o-programa. Acesso em: 24 jun. 2018. 
BRASIL. Ministério da Agricultura, Pecuária e Abastecimento. Proagro. 2018. Disponível em: http://www.agricultura.gov.br/assuntos/riscos-seguro/riscoagropecuario/proagro. Acesso em: 13 set. 2018.

BRASIL. Lei no 11.326, de 24 de julho de 2006. Estabelece as diretrizes para a formulação da Política Nacional da Agricultura Familiar e Empreendimentos Familiares Rurais. Disponível em: http://www.planalto.gov.br/ccivil_03/_ Ato2004-2006/2006/Lei/L11326.htm. Acesso em: 13 set. 2018.

CASTRO, C. M.; RESENDE, G. M.; PIRES, M. J. S. Avaliação dos impactos regionais do Programa Nacional de Fortalecimento da Agricultura Familiar. Texto para Discussão. Brasília: IPEA. 2014.

ORGANIZAÇÃO DAS NAÇÕES UNIDAS PARA A ALIMENTAÇÃO E AGRICULTURA (FAO). Iniciativa regional da FAO aponta agricultura familiar como promotora do desenvolvimento rural sustentável e a agenda 2030. Disponível em: http://www.fao.org/brasil/noticias/detail-events/en/c/1043666. Acesso em: 13 set. 2018.

GAZOLLA, M.; SCHNEIDER, S. Agricultura familiar, segurança alimentar e políticas públicas: uma análise a partir da produção para autoconsumo no território do Alto Uruguai. Porto Alegre: UFRGS, 2004.

GAZOLLA, M.; SCHNEIDER, S. Qual Fortalecimento da Agricultura Familiar? Uma análise do Pronaf crédito de custeio e investimento no Rio Grande do Sul. Revista de Economia e Sociologia Rural, v. 51, p. 45-68, 2013.

INSTITUTO BRASILEIRO DE GEOGRAFIA ESTATÍTICA (IBGE). Censo Agropecuário 2006 - Brasil, Grandes Regiões e Unidades da Federação: notas técnicas. Rio de Janeiro: IBGE, 2009.

INSTITUTOPARANAENSEDEDESENVOLVIMENTOECONÔMICO E SOCIAL (IPARDES). Território Cantuquiriguaçu - Paraná: diagnóstico socioeconômico. Projeto de inclusão social e desenvolvimento rural sustentável PR. Curitiba: IPARDES, 2004.

INSTITUTOPARANAENSEDEDESENVOLVIMENTOECONÔMICO E SOCIAL (IPARDES). Território Cantuquiriguaçu - Paraná: diagnóstico socioeconômico. Projeto de inclusão social e desenvolvimento rural sustentável PR. Curitiba: IPARDES, 2007.

LEITE, S. P. Padrão de financiamento, setor público e agricultura no Brasil. In: LEITE, S. P. (Org.). Políticas públicas e agricultura no Brasil. Porto Alegre: Editora da Universidade, 2001. p. 53-93.

MATTEI, L. PRONAF 10 anos: mapa da produção acadêmica. Brasília: NEAD, 2006.

MATTEI, L. et al. Uma análise dos impactos do PRONAF sobre as economias locais nas regiões nordeste, sudeste e norte do Brasil. In: CONGRESSO DA SOCIEDADE BRASILEIRA DE ECONOMIA, ADMINISTRAÇÃO E SOCIOLOGIA RURAL, 45., 2007, Londrina. Anais [...]. Londrina: SOBER, 2007. p. 1-21.

PRIORI, A. et al. História do Paraná (Séculos XIX eXX). 1. ed. Maringá: Eduem, 2012.v. 1000. 
SCHNEIDER, S. Agricultura familiar e desenvolvimento rural endógeno: elementos teóricos e um estudo de caso. In: FROEHLICH, J. M.; DIESEL, V. (Org.). Desenvolvimento Rural - Tendências e debates contemporâneos. Ijuí: Unijuí, 2006. p. 15-63.

SCHNEIDER, S. Prefácio. In: CONTERATO, M. A et al. (Org.). Mercados e Agricultura Familiar: Interfaces, conexões e conflitos. 1 ed. Porto Alegre: Via Sapiens, 2013.v. 1. p. 8.

SCHNEIDER, S.; AQUINO, J. (Des)caminhos da política de crédito do PRONAF na luta contra pobreza e a desigualdade social no Brasil rural. In: CONFERÊNCIA NACIONAL DE POLITICAS PÚBLICAS CONTRA A POBREZA E A DESIGUALDADE, 1., 2010, Natal. Anais [...]. Natal: UFRN, 2010.v. 1. p. 1-21.

Submetido em: 28/06/2018

Aceito em: 06/11/2018 


\title{
PUBLIC POLICIES AND FAMILY FARMING: AN ANALYSIS OFTHE PRONAF INTERRITORY OF CANTUQUIRIGUAÇU / PR
}

\begin{abstract}
Taking into account the relevance of family farm for rural development as well as its role in the country food supply this paper focuses on the enactment of National Programme of Strengthening of Family Farm (PRONAF), and its impacts on rural development of Cantuquiriguaçu territory, in the state of Paraná, Brazil. The main question addressed here concerns the measure to which policies of financial support for production, investment and trade drive family farmers away from production diversity and local chains, while increasingly articulating with global markets of commodities. This analysis is exploratory and descriptive, aiming at spotting the changes taking place in the territory, based on quantitative and qualitative data gathered through 20 interviews with family farmers, leaders of organizations, and institutions engaged in PRONAF. The descriptive features informed by interviewees are related to farmers themselves, the pattern of landownership in the region, and the destination of credit resources provided by PRONAF in the period of 1995 and 2017. The main results obtained show that this programme has reinforced contradictions typical of family farming. Although keeping traditional cultural, social and economic aspects, farmers have been pushed to the realm of global markets, by dedicating to the production of soybean and maize, and by adopting high yield techniques, similar to those used in large scale farming.
\end{abstract}

Keywords: PRONAF. Rural Development. Family farming.

\section{POLÍTICAS PÚBLICAS Y AGRICULTURA FAMILIAR: UN ANÁLISIS DEL PRONAF EN EL TERRITORIO DEL CANTUQUIRIGUAÇU/PR}

\begin{abstract}
Resumen
Considerando la importancia de la agricultura familiar para el desarrollo rural, así como su papel en el abastecimiento alimentario doméstico, este artículo tiene como objetivo analizar la operacionalización del Programa Nacional de Fortalecimiento de la Agricultura familiar (PRONAF) y sus impactos en el desarrollo rural del territorio del Cantuquiriguaçu, Paraná Brasil. Se cuestiona en qué medida esta política nacional de financiamiento de la producción, inversión y comercialización de la agricultura familiar ha contribuido a un distanciamiento de los productores de las cadenas productivas locales, descargando su diversidad productiva, al mismo tiempo que se articulan cada vez más a los mercados globales de commodities agrícolas. Para ello, este análisis, basado en investigaciones empíricas, tiene carácter exploratorio y descriptivo, buscando identificar aquellas transformaciones en aquel territorio, a través de informaciones recogidas en 20 entrevistas con agricultores familiares, organizaciones e instituciones que participan en la implementación de PRONAF. Por su parte, las características descriptivas fueron detectadas a través de informaciones relativas al perfil de los productores, a la estructura agraria de la región estudiada y la finalidad del crédito concedido por la política desde 1995 hasta 2017 en la región. Los resultados de esta investigación revelan que esta política de crédito ha contribuido al mantenimiento de contradicciones que vienen marcando la agricultura familiar. Mientras los productores preservan sus características tradicionales, también se estimulan a articularse a los mercados globales, produciendo commodities, como soja y maíz, y adoptando un modelo de desarrollo tecnológico típico del agronegocio, en el que predominan grandes propiedades.
\end{abstract}

Palabras clave: PRONAF. Desarrollo rural. Agricultura familiar. 